\title{
An atypical presentation of tuberculosis of the spine
}

\author{
KC Pande, SK Pande and SS Babhulkar \\ Susurut Hospital, Research Centre and Postgraduate Institute of Orthopaedics, Nagpur, India
}

\begin{abstract}
We present a retrospective analysis of 684 patients operated on for a herniated lumbar intervertebral disc. Of the 87 patients with a failed back syndrome, 12 were confirmed to have tuberculous infection of the same disc interval. These patients responded satisfactorily to bracing and a short course of anti-tubercular chemotherapy. Histopathological confirmation of the disease was obtained by CT guided biopsy, and only a few of the patients required repeat surgery. This study highlights one of the atypical presentations of tuberculosis of the spine as a herniated lumbar intervertebral disc and a cause of a failed back syndrome. Advanced imaging techniques such as MRI and CT scans are helpful in the early detection of such conditions.
\end{abstract}

Keywords: intervertebral disc protrusion; spinal infection; tuberculosis of the spine

\section{Introduction}

Tuberculous infection of the spine is still very common in developing countries. The spectrum of the disease has changed over the years, and its incidence is on the rise in the Western world due to immigration and the advent of AIDS. The typical paradiscal involvement is readily recognised and treated. Certain atypical manifestations have also been reported where the diagnosis and treatment is delayed due to lack of awareness of the condition. The presentation of tuberculosis of the spine as a herniated lumbar intervertebral disc and a cause of the failed back syndrome is one such atypical manifestation.

\section{Material and methods}

A retrospective analysis of 684 patients subjected to surgery for a herniated lumbar intervertebral disc treated in our Institute over the 10 years, 1982-1991 was carried out with an average followup of 3 years. There were 87 patients with the failed back syndrome, of which 12 were confirmed to have tuberculosis of the spine involving the operated disc interval.

All patients in this study had presented with classical symptoms and signs resulting from a herniated lumbar intervertebral disc with variable neurology. Plain radiographs of the lumbosacral spine performed at the initial assessment did not show any significant change (Figure 1a).

They were subjected to supervised conservative treatment for a herniated lumbar intervertebral disc, in the form of bed rest, traction and analgesics.

Correspondence: Dr. Ketan C. Pande, M.S. (Orth), D.N.B. 39 Curie Court, Block C-11, Queens Medical Centre, Nottingham NG7 2UH U.K.
On failure to respond to conservative treatment they had surgery after having myelography and in some of the patients a CT scan or MRI study (Figure 1b). The advanced investigations did not show evidence of tuberculous infection of the symptomatic disc space in any of the patients.

At surgery the involved disc was excised and in no instance did we notice granulomatous or caseous material. We did not routinely subject the excised disc to histopathology.

\section{Observations}

All of the 12 patients in the study had prompt relief of symptoms after surgery but returned with a relapse of symptoms within $4-6$ weeks. They were treated with spinal bracing and analgesics. In view of the poor response with this line of treatment, they were investigated with the following possibilities in mind (a) Postoperative disc infection (b) Technical failure, (c) Postoperative spinal instability.

There was no significant change in the haematological profile or any evidence suggestive of pyogenic disc infection on haematological study. There was no evidence of instability in the postoperative radiographs but these Xrays revealed classical changes of paradiscal tuberculosis at the operated disc level (Figure 1c). There was reduction in the height of the involved disc interval with destruction of the adjoining surfaces of the vertebral body.

The tuberculous etiology was confirmed in eight of the patients by CT guided biopsy. In four patients, reexploration and curretage of the lesion was performed for persistent neurological changes and the diagnosis was confirmed by histopathology. 
All of the patients responded well to subsequent spinal bracing and a full course of anti-tubercular chemotherapy.

With this experience in mind, we have been careful in assessing patients who have a herniated lumbar intervertebral disc, who do not respond to adequate conservative treatment. In addition to the 12 patients in this study, in 6 patients we have been successful in detecting early tubercular lesions by a CT scan followed by CT guided biopsy (Figure $2 \mathrm{a}$ and $\mathrm{b}$ ).

\section{Discussion}

Presentation of tuberculosis of the spine as a herniated lumbar intervertebral disc has previously been

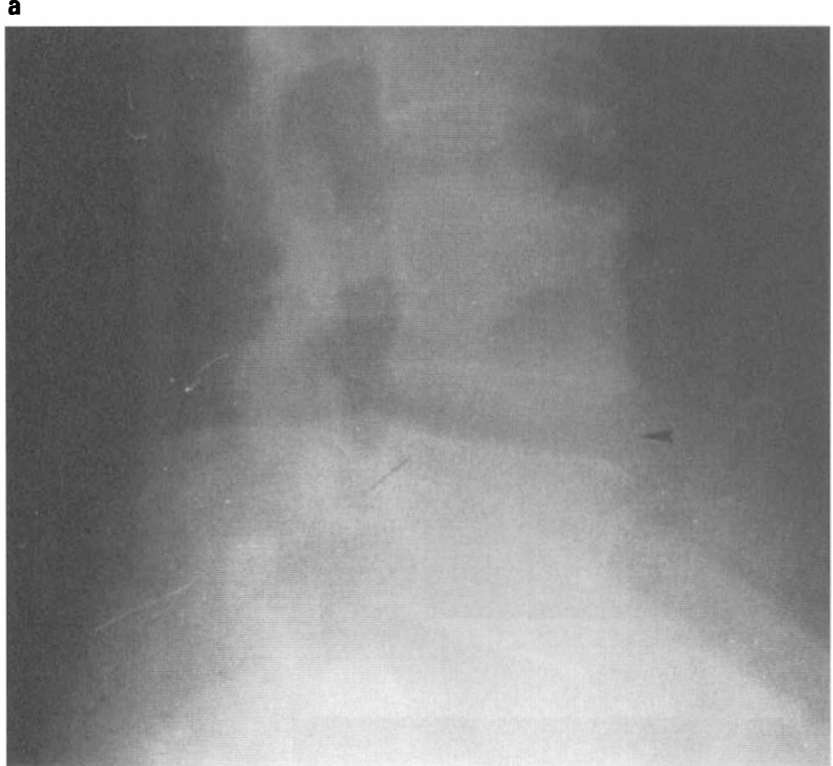

c

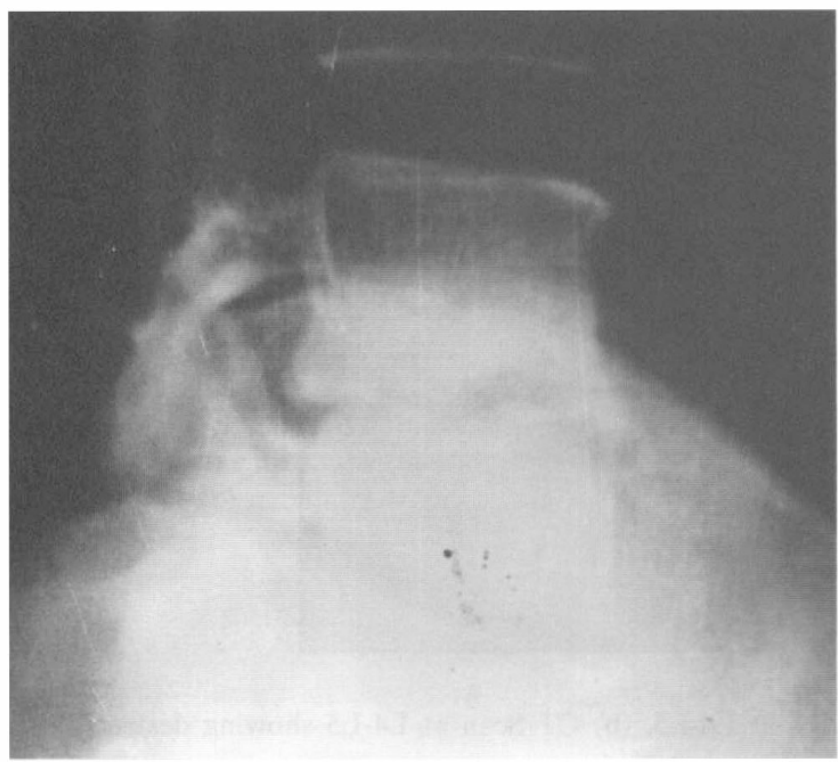

reported. ${ }^{1-5}$ In all of these reports the tubercular etiology could be confirmed only after surgery.

It is hypothesised that the early paradiscal lesion hampers the nutrition of the intervertebral disc which sequestrates out posteriorly and presents as a herniated disc. The other probable mechanisms are secondary infection of the operated disc space from a tubercular focus elsewhere in the body and the flare up of dormant local infection.

The earlier reports have suggested an epidural abscess $^{1,2}$ and spinal epidural granuloma ${ }^{3-5}$ seen intraoperatively as the cause for the presentation of tuberculosis of the spine as a herniated intervertebral disc. Contrary to this, in our study, there was no intraoperative finding to suggest a tuberculous etiology.

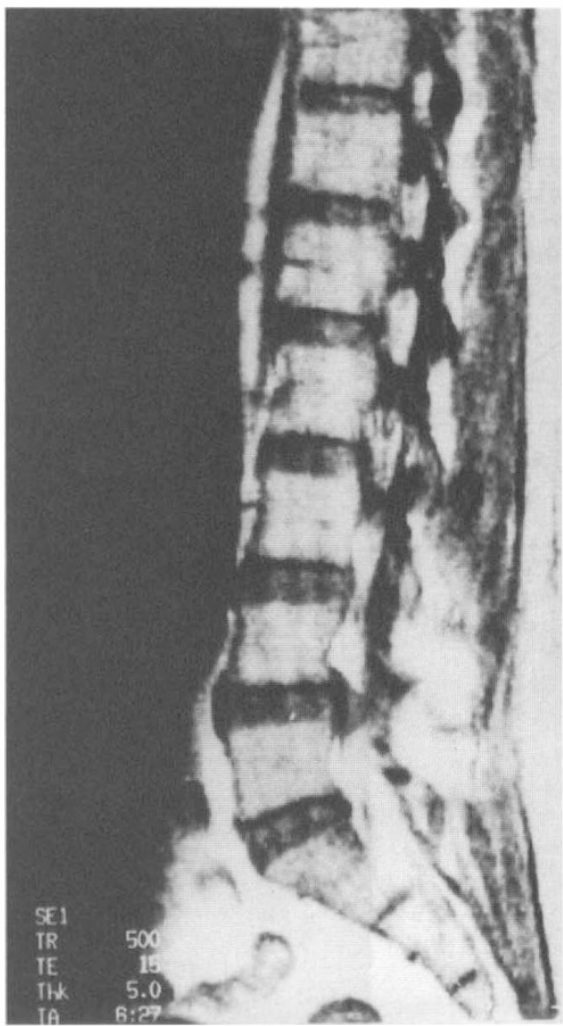

Figure 1 (a) Lateral roentgenogram done at initial assessment: No significant changes observed at L4-L5. (b) MRI scan suggestive of herniated disc L4-L5. No changes in the disc space suggestive of infection. (c) Repeat radiograph (6 weeks Post Surgery) showing Classical changes of Paradiscal spinal tuberculosis with loss of disc space 


Atypical spinal tuberculosis

a

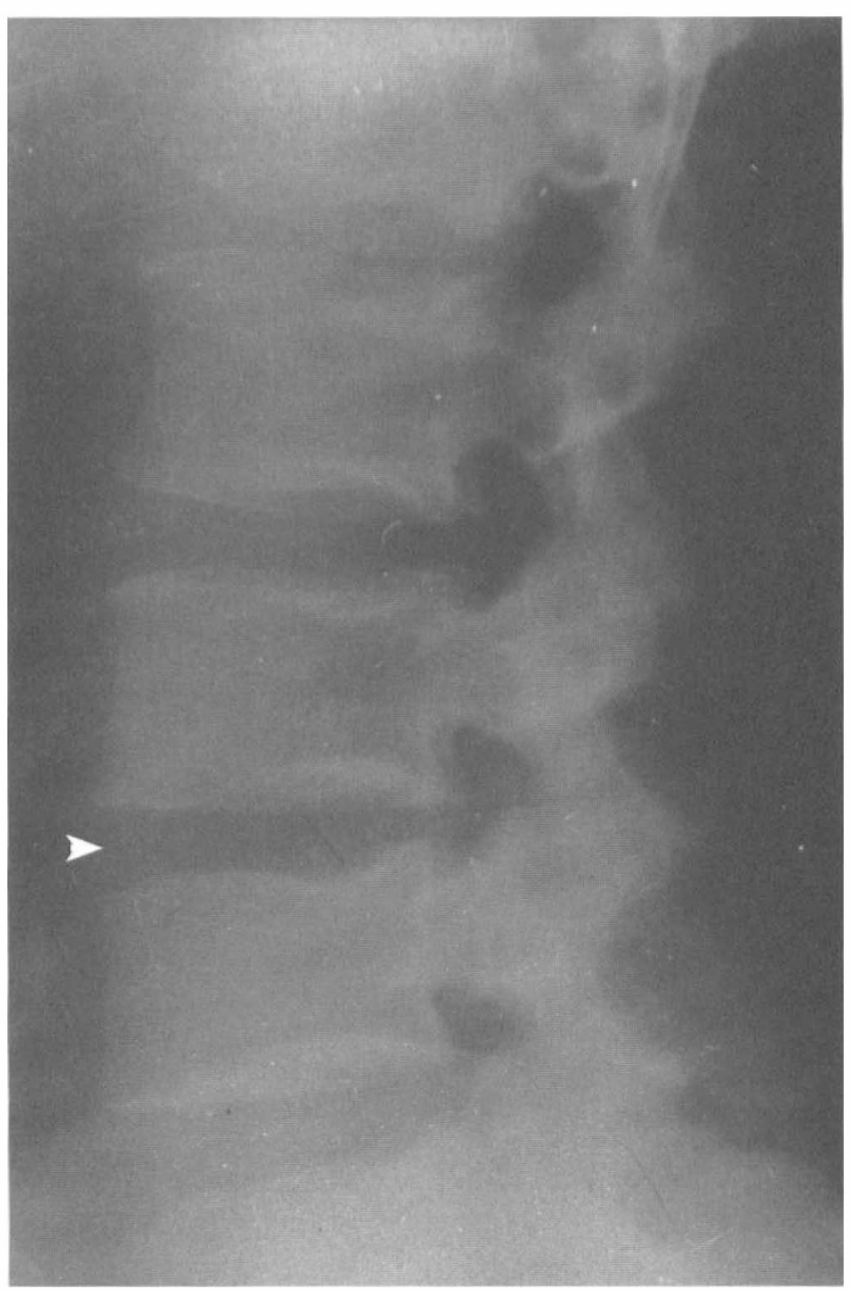

b

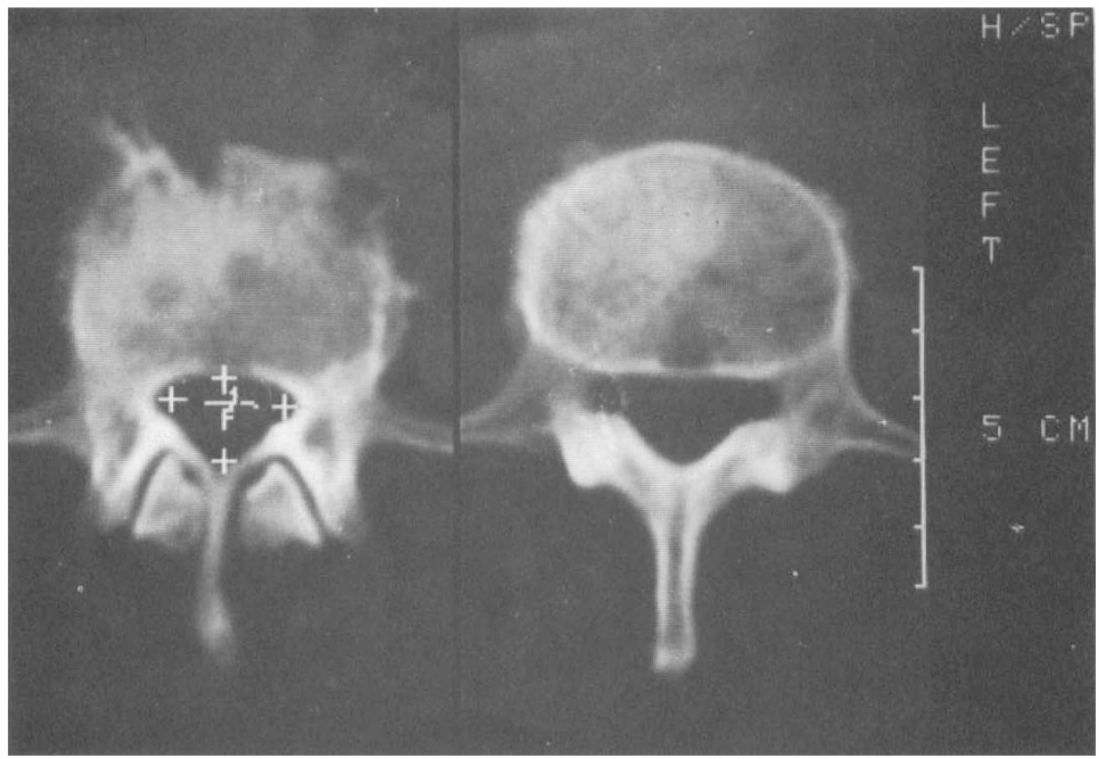

Figure 2 (a) Lateral roentgenogram showing no significant changes at L4-L5. (b) CT Scan at L4-L5 showing destruction of disc surface of L4, changes suggestive of tuberculosis at L4-L5 
The role of the CT scan and MRI scan has been addressed by many workers. ${ }^{6-12}$ MRI scans have been proved to be useful in the early detection of disc interval infection. ${ }^{13}$ In the few patients in this study, where an MRI scan was done to confirm the presence of a herniated intervertebral disc prior to surgery, no changes suggestive of a disc interval infection were seen.

Mondal presented a study of 38 patients of vertebral tuberculosis where the diagnosis was confirmed in 34 by a fine needle aspiration cytology monitored with computed tomography. ${ }^{14}$

\section{Conclusions}

This study highlights one of the atypical presentations of tuberculosis of the spine as a herniated lumbar intervertebral disc, and a cause of the failed back syndrome. We stress the importance of histopathological confirmation of the disease using a less invasive procedure such as a CT guided biopsy especially in patients presenting with atypical features, patients with a herniated lumbar intervertebral disc who do not respond to conservative treatment and patients with a failed back syndrome. A high index of suspicion and early detection by CT guided biopsy helps to avoid unnecessary surgery in these patients.

\section{References}

1 Decker HG, Shapiro SW, Porter HR. Epidural Tuberculous abscess simulating Herniated Lumbar Disc - A case report. Annals of Surgery 1959; 149: 294-296.
2 Keon Cohen BT. Epidural abscess simulating Disc Hernia. $J$ Bone Joint Surg. [ Br] 1968; 50 - B: 128-130.

3 Rao SB, Dinkar I, Rao KS. Extraosseous Extradural Tuberculous Granuloma simulating herniated lumbar disc - A case report. Journal of Neurosurgery 1971; 35: 89-92.

4 Postachini F, Montanaro A. Tuberculous Epidural Granuloma simulating herniated lumbar disc. Clinical Orthopaedics 1980; 148: $182-185$.

5 Babhulkar SS, Tayade WB, Babhulkar SK. Atypical Spinal Tuberculosis. J Bone Joint Surg [Br] 1984; 66 - B: 239-242.

6 Gropper GR, Acker JD, Robertson JH. Computed tomography in Potts Disease. Neurosurgery 1982; 10: 506-508.

7 Hermann G, Mendelson DS, Cohen BA, Train JS. Role of computed tomography in the diagnosis of infectious spondylitis. J Comput Assist Tomog 1983; 7: 961 - 968.

8 Whelan MA, Naidich DP, Post JD, Chase NE. Computed Tomography of spinal tuberculosis. J Comput Assist Tomogr 1983; 7: 25-30.

9 La Berge JM, Brant-Zawadski M. Evaluation of Potts Disease with computed tomography. Neuroradiology 1984; 26: 429-434.

10 deRoos A, van Persijn van Meerten EL, Bloem JL, Bluemm RG. MRI of tuberculous spondylitis. AJR 1986; 146: 79-82.

11 Smith AS et al. MR imaging characteristics of tuberculous spondylitis vs vertebral osteomyelitis. AJNR 1989; 10: 619-625.

12 Hoffman ER, Crosier JH, Cremin BJ. Imaging of children with Spinal tuberculosis. J Bond Joint Surg. [Br] 1993; 75-B: $233-$ 239.

13 Isherwood I, Jenkins JPR. MRI: Technical aspects - CNS and Spine. In: Sutton D. Textbook of Radiology and Medical Imaging. Churchill Livingstone Ed. Fourth, 1987 pp 1654-1690.

14 Mondal A. Cytological diagnosis of vertebral tuberculosis with Fine Needle aspiration biopsy. J Bone Joint Surg. [ Am] 1993; 76A: $181-183$. 